\title{
Consistency of 3D femoral torsion measurement from MRI compared to CT gold standard
}

\author{
Thomas Vincent Häller ${ }^{1 *}$ (D), Pascal Schenk, Lukas Jud ${ }^{1}$, Armando Hoch', Tobias Götschi ${ }^{2}$ and Patrick Oliver Zingg
}

\begin{abstract}
Background: Several hip and knee pathologies are associated with aberrant femoral torsion. Diagnostic workup includes computed tomography (CT) and magnetic resonance imaging (MRI). For three-dimensional (3D) analysis of complex deformities it would be desirable to measure femoral torsion from MRI data to avoid ionizing radiation of $C T$ in a young patient population. 3D measurement of femoral torsion from MRI has not yet been compared to measurements from $C T$ images. We hypothesize that agreement will exist between MRI and CT 3D measurements of femoral torsion.

Methods: $C T$ and MRI data from 29 hips of 15 patients with routine diagnostic workup for suspected femoroacetabular impingement (FAl) were used to generate 3D bone models. 3D measurement of femoral torsion was performed by two independent readers using the method of Kim et al. which is validated for $C$. Inter-modalitiy and inter-reader intraclass correlation coefficients (ICC) were calculated.

Results: Between MRI and CT 3D measurements an ICC of 0.950 (0.898; 0.976) (reader 1) respectively $0.950(0.897 ; 0.976)$ (Reader 2) was found. The ICC $(95 \% \mathrm{Cl})$ expressing the inter-reader reliability for both modalities was $0.945(0.886 ; 0.973)$ for MRI and $0.957(0.910 ; 0.979)$ for $C$, respectively. Mean difference between $C T$ and MRI measurement was $0.42^{\circ}(\mathrm{MRI}-C T$, SD: $\left.2.77^{\circ}, p=0.253\right)$.

Conclusions: There was consistency between 3D measurements of femoral torsion between computer rendered MRI images compared to measurements with the "gold standard" of CT images. ICC for inter-modality and inter-reader consistency indicate excellent reliability. Accurate, reliable and reproducible 3D measurement of femoral torsion is possible from MRl images.
\end{abstract}

Keywords: 3D, Three-dimensional, Femoral torsion, Antetorsion, FAl, MRI

\section{Background}

Femoral torsion was described as the angle between the femoral neck and the femoral condyles by Julius Wolff in 1868 [1, 2]. Several pathologies are associated with aberrant femoral torsion, such as slipped capital femoral epiphysis, developmental dysplasia of the hip and earlyonset hip osteoarthritis [3-5]. There is an association

\footnotetext{
* Correspondence: thomas.haeller@ksb.ch

1 Department of Orthopedics, Balgrist University Hospital, University of Zurich, Forchstrasse 340, 8008 Zurich, Switzerland

Full list of author information is available at the end of the article
}

between reduced femoral antetorsion and cam-type femoroacetabular impingement (FAI) [6-8].

Clinical quantification of femoral torsion is not reliable $[6,9,10]$. Initially standard radiographs such as the Dunn and modified Dunn view were used $[1,2,11]$. This has been replaced by more precise computer tomography $(\mathrm{CT})$ and magnetic resonance imaging (MRI) measurements with various differences in measurement techniques for both of them $[12,13]$. All these conventional methods that use cross sectional CT, MRI or ultrasound are two-dimensional (2D) imaging methods

(c) The Author(s). 2021 Open Access This article is licensed under a Creative Commons Attribution 4.0 International License, which permits use, sharing, adaptation, distribution and reproduction in any medium or format, as long as you give appropriate credit to the original author(s) and the source, provide a link to the Creative Commons licence, and indicate if changes were made. The images or other third party material in this article are included in the article's Creative Commons licence, unless indicated otherwise in a credit line to the material. If material is not included in the article's Creative Commons licence and your intended use is not permitted by statutory regulation or exceeds the permitted use, you will need to obtain permission directly from the copyright holder. To view a copy of this licence, visit http://creativecommons.org/licenses/by/4.0/ The Creative Commons Public Domain Dedication waiver (http://creativecommons.org/publicdomain/zero/1.0/) applies to the data made available in this article, unless otherwise stated in a credit line to the data. 
and encounter problems representing the complex, three-dimensional (3D) structure of the femur. To overcome the limitations of conventional 2D imaging methods, a 3D imaging method was developed by Kim et al. with greatly improved accuracy compared to conventional $2 \mathrm{D}$ imaging methods $[14,15]$. These $3 \mathrm{D}$ measurements require $\mathrm{CT}$ imaging which has become the "gold standard" for quantification of 3D bone morphology in patients with structural hip disorders, such as FAI [16-20]. But using CT to characterize 3D hip morphology in the mostly young population of FAI patients is controversial due to potential harmful ionizing radiation exposure (about 4-5 $\mathrm{mSv}$ per $\mathrm{CT}$ ) with a small lifetime attributable risk $(0.034-0.177 \%$ for a 20 -yearold) but a large relative risk (5-17 times) of cancer compared with radiographs alone [21, 22]. On the other hand MRI is useful to evaluate intra- and extra-articular soft tissue structures and the cartilage [23-28]. Thereby it provides essential predictors for the benefit of FAI surgery [29].

It would be preferable to measure the femoral torsion in 3D from MRI images without the need of additional CT imaging and consequently avoiding harmful ionizing radiation and save healthcare resources.

To understand complex deformities 3D measurements can be helpful. That is why they are desirable to get, best with as little as possible additional expenses. Correction of such complex deformities in particular may benefit from 3D analysis and 3D planning of the deformity correction to minimize errors which could lead to biomechanical alteration [30-32]. The required 3D bone models can be generated from CT or MRI data [33-37].

However, the proof that 3D femoral torsion measurements from MRI generated 3D models correspond with measurements from CT generated 3D models has not occurred yet. The aim of this paper was to investigate if 3D measurement of femoral torsion from MRI yielded comparable results as measurement from CT data. We hypothesized that agreement existed between reconstructed MRI and CT 3D measurements of femoral torsion.

\section{Methods}

\section{Patient selection}

The local ethical committee approved this study (BASEC Number 2012-02242) and all patients gave their informed written consent for their participation and the publication of this study.

We retrospectively analysed CT and MRI data of 29 hips from 15 patients ( 7 female, 8 male) who had routine workup for clinical symptoms suggestive for FAI between May and November 2019. The average age at the time of the scans was 32 years (range $21-47$ years). Fourteen patients had an MRI and a CT scan of both sides.
One patient had imaging only of the right side, which lead to a total of 29 hips (15 right hips, 14 left hips) with complete MRI and CT dataset.

\section{Imaging and segmentation}

All CT scans were performed at our institution, using a 64-detector row CT scanner (Somatom Edge Plus, Siemens Healthcare, Erlangen, Germany), slice thickness was $1.0 \mathrm{~mm}$. The protocol was as follows: Feet first, supine; central positioning of the pelvis, slightly internal rotation of the legs; image centered in the middle of the pelvis slightly above the iliac crest. The proximal femur was scanned from just above the iliac crest to the end of the lesser trochanter. The distal femur was scanned from the femoral condyles to the joint line.

MRI were also performed at our institution using a 3.0 Tesla MR scanner (Magnetom Skyra 3.0 T; Siemens Healthcare, Erlangen, Germany). The protocol was as follows: Coronal 3D T1-weighted VIBE-Dixon sequence (femur, bilateral): Slice thickness $1.5 \mathrm{~mm}$, FOV $348 \times 655 \mathrm{~mm}$, Echo time $5.7 \mathrm{~ms}$, Repetition Time $2.5 \mathrm{~ms}$, number of images 88 .

CT and MRI scans were performed on the same day. No intraarticular contrast was given for CT scans nor for MRI.scans.

\section{D measurement method}

3D bone models of all included femurs were generated from CT and MRI data using the global thresholding and region growing functionality of a standard segmentation software (Mimics Medical 19.0, Materialise NV, Leuven, Belgium). Segmentation of the MRI was performed using the T1-weighted VIBE-Dixon sequence. The bone models were imported into the in-house developed surgical planning software CASPA (Balgrist CARD AG, Zurich, Switzerland) for 3D measurement of the femoral torsion (Figs. 1a and b and 2a and b).

3D femoral torsion measurements were performed subsequently using a method based on Kim et al. [15]. Thereby, femoral torsion is defined as the angle between the femoral neck axis and the tangent to the posterior condyles, both projected to a plane perpendicular to the anatomical axis (Fig. 3). The femoral neck axis is defined as the line connecting the center of the femoral head and the center of the cross-section at the narrowest point of the femoral neck. First, the center of the femoral head was determined by fitting a sphere to the femoral head, minimizing the distance to a user-selected region on the femoral head [38]. Second, a plane was manually fit to the narrowest diameter of the femoral neck, perpendicular to the estimated femoral neck axis. The center point of the intersection between this plane and the femoral bone was connected with the center of the femoral head, resulting in the femoral neck axis. 

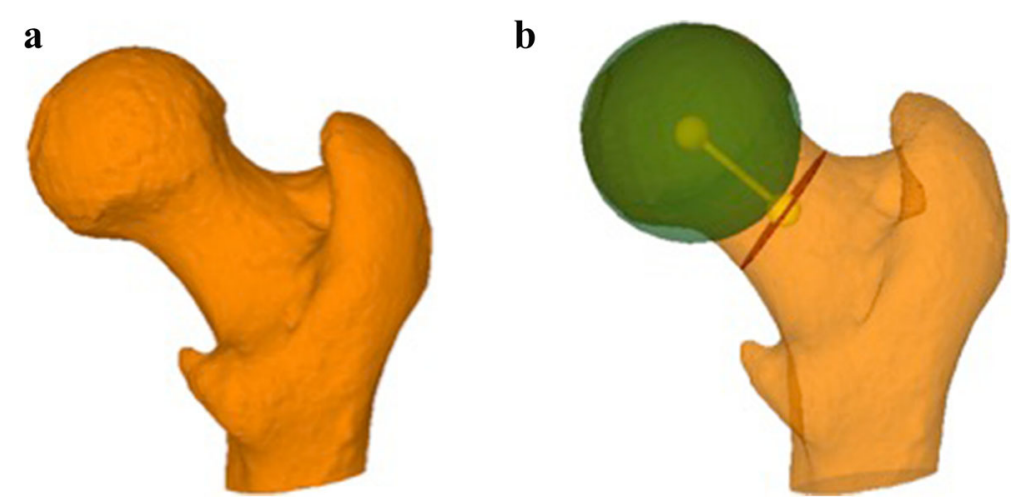

Fig. 1 a 3D model of the proximal femur from $C T$ data. $\mathbf{b}$ The same 3D model then 1a with the sphere fitted to the femoral head (green), the cross section at the narrowest point of the femoral neck (red) and the femoral neck axis (yellow), connecting the two centers. Both figures were created by the authors using the in-house developed surgical planning software CASPA (Balgrist CARD AG, Zurich, Switzerland)

The tangent to the posterior condyles was determined by manually fitting a plane to the posterior side of the femur, in a way that the plane passed through the most posterior points of the femoral condyles and the most posterior point of the greater trochanter. The condylar tangent was then defined as a line between most posterior points of the femoral condyles.

Finally, the anatomical femoral axis was defined between the centre of an axial cross-section located in the middle of the tip of the lesser and the greater trochanter and the centre of an axial cross-section just above the femoral condyles. By using the three defined axes (i.e. femoral neck axis, femoral condylar axis, and anatomical femoral axis), the 3D femoral torsion was calculated in MATLAB (Version 2019a, The MathWorks Inc., Natick MA, USA). For inter-reader reliability all 3D femoral torsion measurements were performed by two independent readers ( $\mathrm{TH}$ and $\mathrm{LJ})$.

\section{Statistical analysis}

Inter-reader and inter-modality reliability were assessed with intraclass correlation coefficients (ICC) based on a two-way random effects and a two-mixed effects model, respectively. Absolute agreement based on single measures was analyzed. These analyses were stratified by reader or by modality as applicable. The standard error of measurement was computed to yield an estimate of the expected error associated with a measurement. To test for a systematic difference in angle measurements between the modalities, a paired t-test was conducted. This test was applied on the pooled data from both readers. Intra-observer variability between $\mathrm{CT}$ and MRI
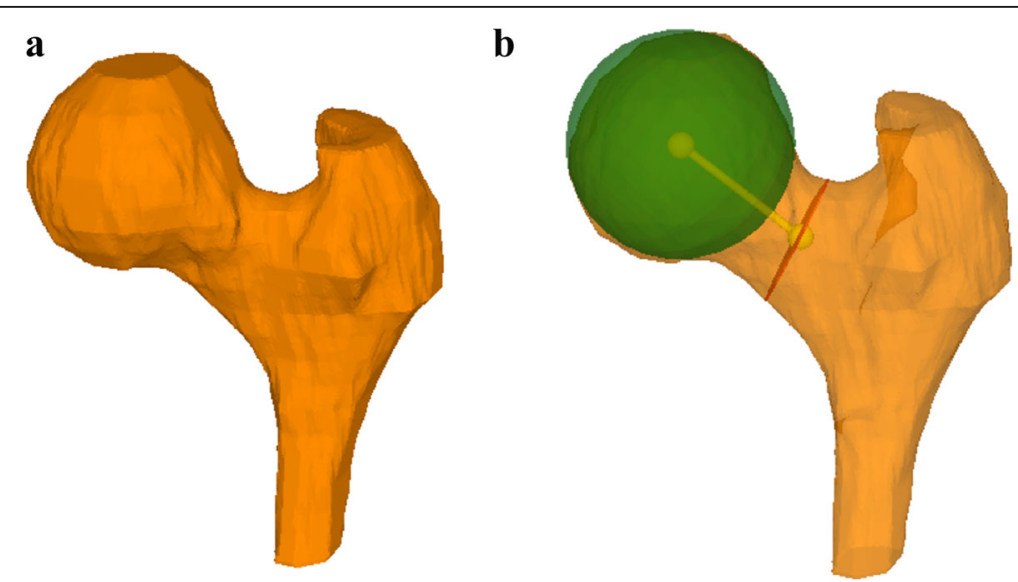

Fig. 2 a 3D model of the proximal femur from MRI data. (Note the much less precise osseous morphology compared to the CT model shown in Fig. 1). $\mathbf{b}$ The same 3D model with the sphere fitted to the femoral head (green), the cross section at the narrowest point of the femoral neck (red) and the femoral neck axis (yellow), connecting the two centers. Both figures were created by the authors using the in-house developed surgical planning software CASPA (Balgrist CARD AG, Zurich, Switzerland) 


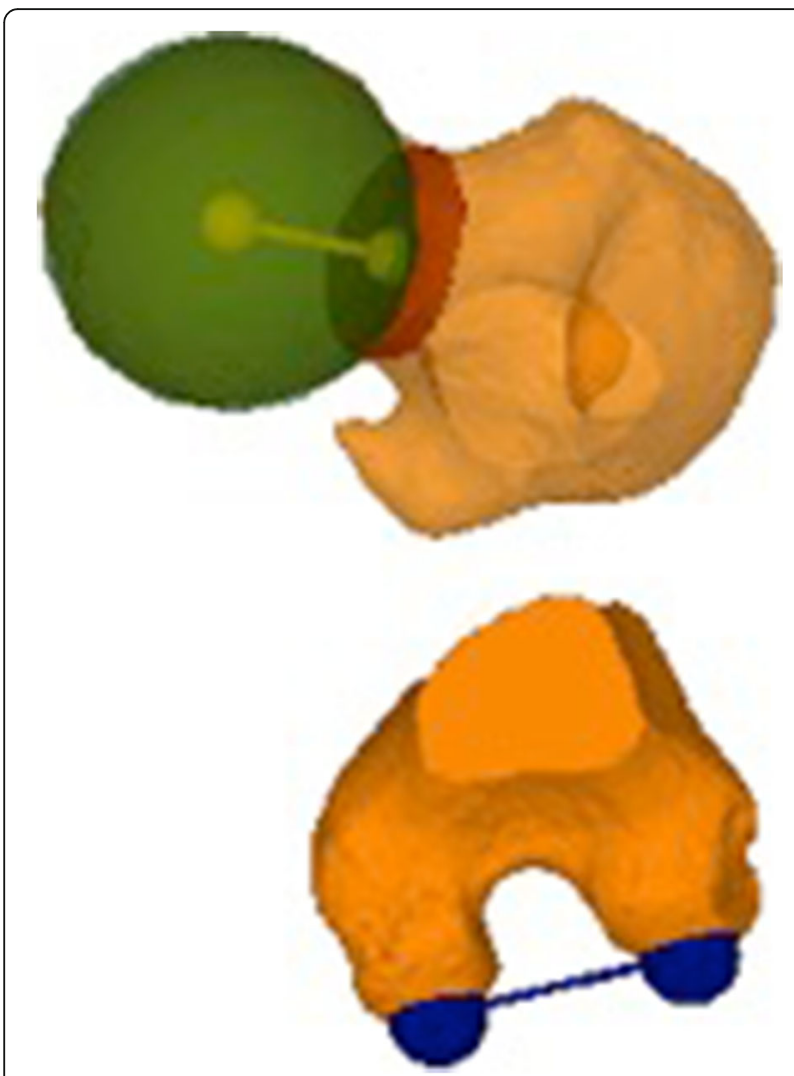

Fig. 3 Femoral condylar axis (blue) and femoral neck axis (yellow) of a $C T$ rendered image. The figure was created by the authors using the in-house developed surgical planning software CASPA (Balgrist CARD AG, Zurich, Switzerland) for both readers were also assessed. Analysis was performed with SPSS (IBM SPSS Statistics for Windows, Version 26.0. Armonk, NY: IBM Corp.). P-values below 0.05 were considered statistically significant.

\section{Results}

Individual 3D measurement values of both readers from CT and MRI data for all 29 hips are shown in Table 1. The range of the measured 3D femoral torsion was from $-16.4^{\circ}$ to $28.2^{\circ}$.

\section{Inter-modality reliability}

The ICC (95\% CI) expressing the inter-modality reliability for both assessed modalities was $0.950(0.898 ; 0.976)$ (reader 1$)$ and $0.950(0.897 ; 0.976)$ (reader 2), respectively. The standard error of measurement (SEM) was $1.97^{\circ}$ (reader 1 ) and $1.92^{\circ}$ (reader 2), respectively (Fig. 4).

The comparison of angle measurements conducted with either modality yielded a mean difference of $0.42^{\circ}$ (MRI - CT, SD: $2.77^{\circ}, p=0.253$ ).

\section{Inter-reader reliability}

The ICC (95\% CI) expressing the inter-reader-reliability for both modalities was $0.945(0.886 ; 0.973)$ for MRI and 0.957 (0.910; 0.979) for CT. The standard error of measurement (SEM) was $2.01^{\circ}(\mathrm{MRI})$ and $1.83^{\circ}(\mathrm{CT})$, respectively (Fig. 5).

\section{Intra-observer variability}

The mean intra-observer variability between $\mathrm{CT}$ and MRI was 1.51 (reader 1 ) respectively 1.62 (reader 2).

Table $13 \mathrm{D}$ torsional measurements from $\mathrm{CT}$ and MRI from reader 1 and reader 2. Values in ${ }^{\circ}$

\begin{tabular}{|c|c|c|c|c|c|c|c|c|}
\hline Subject & $\begin{array}{l}\text { CT } \\
\text { Reader } 1 \\
\text { RIGHT HIP }\end{array}$ & $\begin{array}{l}\text { MRI } \\
\text { Reader } 1\end{array}$ & $\begin{array}{l}C T \\
\text { Reader } 2\end{array}$ & $\begin{array}{l}\text { MRI } \\
\text { Reader } 2\end{array}$ & $\begin{array}{l}\text { CT } \\
\text { Reader } 1 \\
\text { LEFT HIP }\end{array}$ & $\begin{array}{l}\text { MRI } \\
\text { Reader } 1\end{array}$ & $\begin{array}{l}C T \\
\text { Reader } 2\end{array}$ & $\begin{array}{l}\text { MRI } \\
\text { Reader } 2\end{array}$ \\
\hline 1 & $14.5^{\circ}$ & $14.9^{\circ}$ & $16.4^{\circ}$ & $18.1^{\circ}$ & $17.5^{\circ}$ & $16.5^{\circ}$ & $19.4^{\circ}$ & $16.2^{\circ}$ \\
\hline 2 & $-9.4^{\circ}$ & $-0.6^{\circ}$ & $-5.3^{\circ}$ & $-4.1^{\circ}$ & $-4.7^{\circ}$ & n.a. & $-0.2^{\circ}$ & n.a. \\
\hline 3 & $15.2^{\circ}$ & $14.1^{\circ}$ & $13.1^{\circ}$ & $14.2^{\circ}$ & $18.2^{\circ}$ & $18.8^{\circ}$ & $18.3^{\circ}$ & $21.4^{\circ}$ \\
\hline 4 & $12.4^{\circ}$ & $8.9^{\circ}$ & $15.1^{\circ}$ & $11.4^{\circ}$ & $9.5^{\circ}$ & $13.0^{\circ}$ & $13.5^{\circ}$ & $16.6^{\circ}$ \\
\hline 5 & $7.6^{\circ}$ & $10.9^{\circ}$ & $4.6^{\circ}$ & $9.5^{\circ}$ & $10.0^{\circ}$ & $12.5^{\circ}$ & $10.2^{\circ}$ & $8.3^{\circ}$ \\
\hline 6 & $10.5^{\circ}$ & $11.2^{\circ}$ & $9.1^{\circ}$ & $6.5^{\circ}$ & $4.7^{\circ}$ & $7.3^{\circ}$ & $6.2^{\circ}$ & $7.5^{\circ}$ \\
\hline 7 & $11.9^{\circ}$ & $8.6^{\circ}$ & $8.1^{\circ}$ & $5.5^{\circ}$ & $9.1^{\circ}$ & $10.4^{\circ}$ & $8.1^{\circ}$ & $11.6^{\circ}$ \\
\hline 8 & $20.7^{\circ}$ & $18.6^{\circ}$ & $21.4^{\circ}$ & $19.3^{\circ}$ & $28.2^{\circ}$ & $27.4^{\circ}$ & $27.0^{\circ}$ & $24.2^{\circ}$ \\
\hline 9 & $5.4^{\circ}$ & $7.6^{\circ}$ & $8.0^{\circ}$ & $8.2^{\circ}$ & $9.0^{\circ}$ & $6.8^{\circ}$ & $10.6^{\circ}$ & $11.4^{\circ}$ \\
\hline 10 & $1.9^{\circ}$ & $0.2^{\circ}$ & $1.0^{\circ}$ & $2.8^{\circ}$ & $2.8^{\circ}$ & $3.2^{\circ}$ & $5.8^{\circ}$ & $6.1^{\circ}$ \\
\hline 11 & $5.4^{\circ}$ & $3.3^{\circ}$ & $0.2^{\circ}$ & $0.8^{\circ}$ & $20.8^{\circ}$ & $20.6^{\circ}$ & $18.3^{\circ}$ & $19.0^{\circ}$ \\
\hline 12 & $-7.2^{\circ}$ & $-4.1^{\circ}$ & $-2.3^{\circ}$ & $-7.2^{\circ}$ & $-15.8^{\circ}$ & $-16.4^{\circ}$ & $-13.2^{\circ}$ & $-16.0^{\circ}$ \\
\hline 13 & $7.4^{\circ}$ & $7.4^{\circ}$ & $10.0^{\circ}$ & $8.5^{\circ}$ & $3.3^{\circ}$ & $3.1^{\circ}$ & $4.8^{\circ}$ & $6.2^{\circ}$ \\
\hline 14 & $14.8^{\circ}$ & $15.8^{\circ}$ & $14.5^{\circ}$ & $13.0^{\circ}$ & $17.1^{\circ}$ & $13.8^{\circ}$ & $17.1^{\circ}$ & $18.2^{\circ}$ \\
\hline 15 & $10.1^{\circ}$ & $14.4^{\circ}$ & $14.4^{\circ}$ & $17.6^{\circ}$ & $2.6^{\circ}$ & $7.3^{\circ}$ & $5.4^{\circ}$ & $12.2^{\circ}$ \\
\hline
\end{tabular}




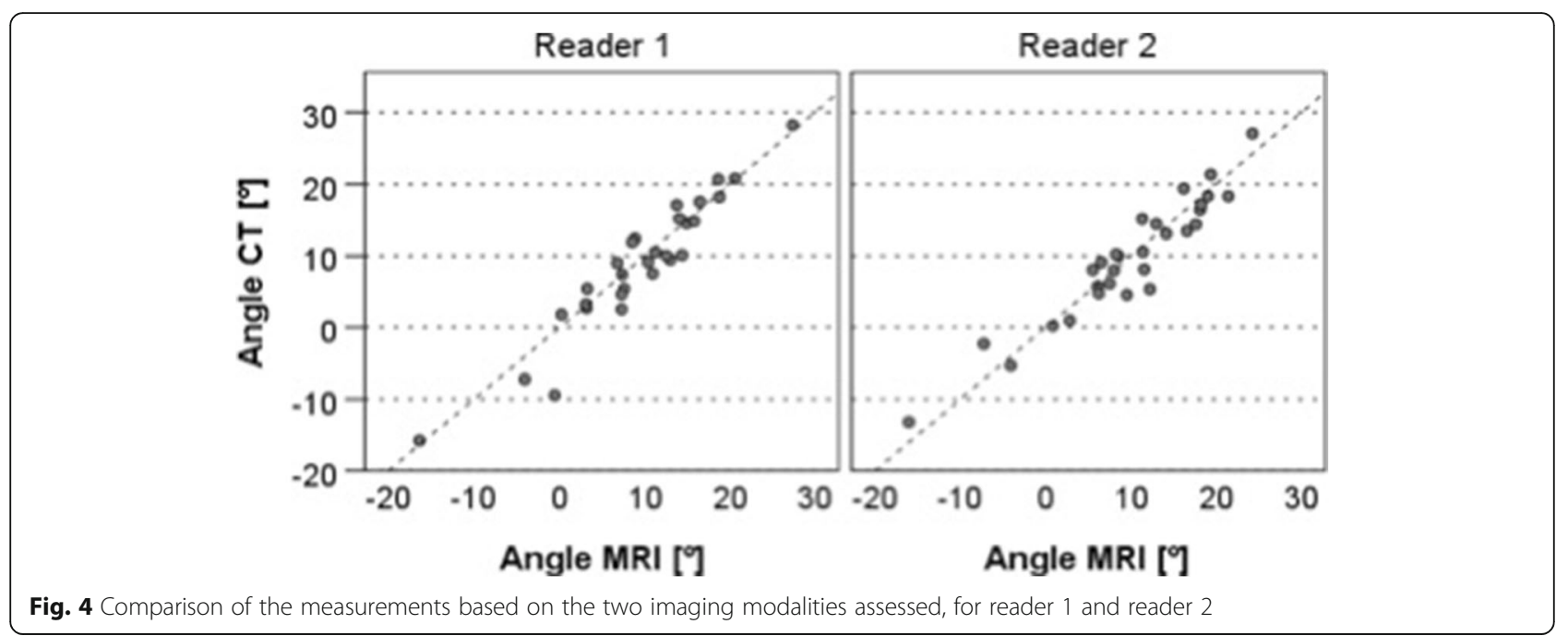

\section{Discussion}

The most important finding of the present study is that consistency exists between 3D measurements of femoral torsion from MRI and CT reconstructed bone models. The mean difference of the modalities was very low with $0.42^{\circ}$ (MRI - CT, SD: $2.77^{\circ}, p=0.253$ ). Our hypothesis was confirmed further by an ICC for the inter-modality reliability of $>0.9$ expressing an excellent reliability [39]. Additionally, inter-reader reliability was estimated to be excellent indicating high reproducibility of the measurements. The SEM was $1.97^{\circ}$ (reader 1 ) respectively $1.92^{\circ}$ (reader 2). In our opinion the MRI can still provide valuable information with a measurement error of $2^{\circ}$.

Three dimensional femoral torsion measurements with computer rendered CT images using the 3D modeling method described by Kim et al. is the "gold standard" [15]. On computer rendered MRI data the anatomy may be depicted less precise than on CT data, since some landmarks (i.e. the lesser trochanter) are more difficult to identify (see Figs. 1 and 2), slice thickness of MRI rotational sequences is usually higher (i.e. $1 \mathrm{~mm}$ for CT vs. $1.5 \mathrm{~mm}$ for MRI in this study) and soft tissue is more difficult to distinguish from bone and cartilaginous tissue during the segmentation process. Surprisingly, these large differences do not seem to have a significant impact on the final result of the $3 \mathrm{D}$ torsional measurements. MRI is more time consuming than CT (about 91 seconds vs. 5 seconds) and so there is a potential for movement of the patient's leg between scanning the proximal femur and the condylar region and thereby influencing the torsional angle. But still the chance of complete failure of the MRI is negliable. Anyhow, this is a hypothesis of the authors and could not be proved by this study. It is therefore crucial that the rotational sequences are scanned as quickly as possible in succession. The great advantage of MRI is that it can analyze

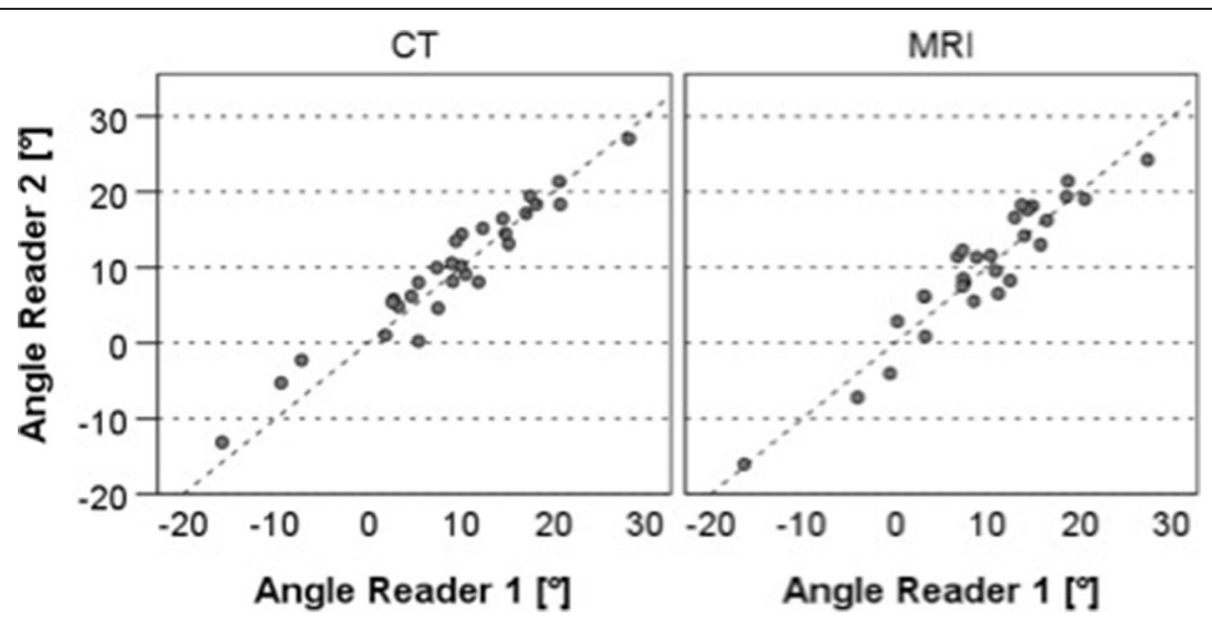

Fig. 5 Comparison of the measurements performed by the two readers for both image modalities 
cartilage and soft tissue disorders in addition to bone conditions whereas the $\mathrm{CT}$ is considered to be more precise for evaluating the bony anatomy. However, previous studies have shown that MRI can be used as a precise alternative to CT for evaluation of 3D osseous morphology in the shoulder and knee [33, 36]. Moreover, the identification and location of cam-type morphology was equivalent using 3D osseous reconstructions of the femur generated from $3 \mathrm{~T}$ MRI and CT scans [40]. However, none of these studies could show that 3D measurement of patients' femoral torsion could be performed from MRI data instead of CT data. To our knowledge this is the first study that calculates 3D femoral torsion using MRI data comparing it to 3D femoral torsion measurements form CT data.

Our results indicate that 3D measurement of femoral torsion can be performed using MRI data, making the routinely performed $\mathrm{CT}$ imaging for measuring the $3 \mathrm{D}$ torsional angle questionable and, thus, giving a potential to reduce healthcare resources and harmful ionizing radiation.

We acknowledge limitations of our study. The performed measurement was not analyzed for subgroups of patients with specific torsional angles (i.e. normal, too high, too low torsion). Therefore we can only state that the two measurement methods are comparable within the range tested in our collective. The number of patients in this study would be too small to analyze subgroups with "extreme" torsional angles and the goal was primarily to evaluate the accuracy of the measurement from MRI data in general and should be considered as a preliminary study that serves as proof of concept.

Further MR image segmentation was performed by a person without prior academic training in the matter but he was carefully instructed to carry out the task. Individuals with different levels of training may yield varying results.

\section{Conclusions}

Accurate 3D measurement of femoral torsion is possible from MRI images. It shows consistency compared to measurements with the "gold standard" of CT images in our collective of 29 hips.

\section{Abbreviations}

2D: Two-dimensional; 3D: Three-dimensional; CT: Computer Tomography; FAI: Femoroacetabular impingement; ICC: Intraclass correlation coefficients; MRI: Magnetic Resonance Imaging

\section{Acknowledgements}

The authors would like to thank Tabitha Roth from the ROCS Team for her help with the 3D measurement technique and Reto Sutter, MD from the radiology department for his support.

\section{Authors' contributions}

TVH, PS and POZ designed the study. TVH, $\mathrm{AH}$ and $\sqcup$ performed the measurements and data acquisition. TVH wrote the manuscript. TVH and $\mathrm{AH}$ prepared the graphics. TG performed the statistical analysis. PS, TG and POZ revised the manuscript critically. All authors read and approved the final manuscript.

\section{Funding}

No funding was received for conducting this study.

Availability of data and materials

Anonymized source data can be obtained from the corresponding author on reasonable request.

\section{Declarations}

Ethics approval and consent to participate

The local ethical committee approved this study (Zurich Cantonal Ethics Commission, BASEC Number 2012-02242). Informed written consent was obtained from all individual participants included in the study.

Consent for publication

Not applicable.

Competing interests

The authors declare that they have no competing interests.

\section{Author details}

'Department of Orthopedics, Balgrist University Hospital, University of Zurich, Forchstrasse 340, 8008 Zurich, Switzerland. ${ }^{2}$ Computer Assisted Research and Development Group, Balgrist University Hospital, University of Zurich, Forchstrasse 340, 8008 Zurich, Switzerland.

Received: 21 February 2021 Accepted: 16 August 2021

Published online: 28 August 2021

\section{References}

1. Fabry G. Torsion of the femur. Acta Orthop Belg. 1977:43(4):454-9.

2. Dunlap K, Shands AR Jr, Hollister LC Jr, Gaul JS Jr, Streit HA. A new method for determination of torsion of the femur. J Bone Joint Surg Am. 1953;35A(2):289-311.

3. Tonnis D, Heinecke A. Diminished femoral antetorsion syndrome: a cause of pain and osteoarthritis. J Pediatr Orthop. 1991;11(4):419-31. https://doi.org/1 0.1097/01241398-199107000-00001.

4. Wedge $\mathrm{JH}$, Wasylenko MJ. The natural history of congenital disease of the hip. J Bone Joint Surg (Br). 1979;61-B(3):334-8. https://doi.org/10.1302/0301620X.61B3.158025.

5. Gelberman RH, Cohen MS, Shaw BA, Kasser JR, Griffin PP, Wilkinson RH. The association of femoral retroversion with slipped capital femoral epiphysis. J Bone Joint Surg Am. 1986;68(7):1000-7. https://doi.org/10.2106/00004623-1 98668070-00006.

6. Botser IB, Ozoude GC, Martin DE, Siddiqi AJ, Kuppuswami S, Domb BG. Femoral anteversion in the hip: comparison of measurement by computed tomography, magnetic resonance imaging, and physical examination. Arthroscopy. 2012;28(5):619-27. https://doi.org/10.1016/j.arthro.2011.10.021.

7. Sutter R, Dietrich TJ, Zingg PO, Pfirrmann CW. Femoral antetorsion: comparing asymptomatic volunteers and patients with femoroacetabular impingement. Radiology. 2012;263(2):475-83. https://doi.org/10.1148/ra diol.12111903

8. Tibor LM, Liebert G, Sutter R, Impellizzeri FM, Leunig M. Two or more impingement and/or instability deformities are often present in patients with hip pain. Clin Orthop Relat Res. 2013;471(12):3762-73. https://doi.org/1 0.1007/s11999-013-2918-6.

9. Souza RB, Powers CM. Concurrent criterion-related validity and reliability of a clinical test to measure femoral anteversion. J Orthop Sports Phys Ther. 2009;39(8):586-92. https://doi.org/10.2519/jospt.2009.2996.

10. Maier C, Zingg P, Seifert B, Sutter R, Dora C. Femoral torsion: reliability and validity of the trochanteric prominence angle test. Hip Int. 2012;22(5):534-8. https://doi.org/10.5301/HIP.2012.9352.

11. Dunn DM. Anteversion of the neck of the femur; a method of measurement. J Bone Joint Surg (Br). 1952;34-B(2):181-6. https://doi.org/1 0.1302/0301-620X.34B2.181.

12. Sutter R, Dietrich TJ, Zingg PO, Pfirrmann CW. Assessment of femoral antetorsion with MRI: comparison of oblique measurements to standard 
transverse measurements. AJR Am J Roentgenol. 2015;205(1):130-5. https:// doi.org/10.2214/AJR.14.13617.

13. Tomczak RJ, Guenther KP, Rieber A, Mergo P, Ros PR, Brambs HJ. MR imaging measurement of the femoral antetorsional angle as a new technique: comparison with CT in children and adults. AJR Am J Roentgenol. 1997;168(3):791-4. https://doi.org/10.2214/ajr.168.3.9057536.

14. Kim JS, Park TS, Park SB, Kim JS, Kim IY, Kim SI. Measurement of femoral neck anteversion in 3D. Part 1: 3D imaging method. Med Biol Eng Comput. 2000;38(6):603-9. https://doi.org/10.1007/BF02344864.

15. Kim JS, Park TS, Park SB, Kim JS, Kim IY, Kim SI. Measurement of femoral neck anteversion in 3D. Part 2: 3D modelling method. Med Biol Eng Comput. 2000;38(6):610-6. https://doi.org/10.1007/BF02344865.

16. Bedi A, Dolan M, Magennis E, Lipman J, Buly R, Kelly BT. Computer-assisted modeling of osseous impingement and resection in femoroacetabular impingement. Arthroscopy. 2012;28(2):204-10. https://doi.org/10.1016/j.a rthro.2011.11.005.

17. Heyworth BE, Dolan MM, Nguyen JT, Chen NC, Kelly BT. Preoperative threedimensional $C T$ predicts intraoperative findings in hip arthroscopy. Clin Orthop Relat Res. 2012;470(7):1950-7. https://doi.org/10.1007/s11999012-2331-6.

18. Kang RW, Yanke AB, Espinoza Orias AA, Inoue N, Nho SJ. Emerging ideas: novel 3-D quantification and classification of cam lesions in patients with femoroacetabular impingement. Clin Orthop Relat Res. 2013;471(2):358-62. https://doi.org/10.1007/s11999-012-2693-9

19. Khan $\mathrm{O}$, Witt J. Evaluation of the magnitude and location of cam deformity using three dimensional CT analysis. Bone Joint J. 2014;96-B(9):1167-71. https://doi.org/10.1302/0301-620X.96B9.33555

20. Milone MT, Bedi A, Poultsides L, Magennis E, Byrd JW, Larson CM, et al. Novel CT-based three-dimensional software improves the characterization of cam morphology. Clin Orthop Relat Res. 2013;471(8):2484-91. https://doi. org/10.1007/s11999-013-2809-x.

21. Amis ES Jr, Butler PF, Applegate KE, Birnbaum SB, Brateman LF, Hevezi JM, et al. American College of Radiology white paper on radiation dose in medicine. J Am Coll Radiol. 2007;4(5):272-84. https://doi.org/10.1016/j.jacr.2 007.03.002.

22. Wylie JD, Jenkins PA, Beckmann JT, Peters CL, Aoki SK, Maak TG. Computed tomography scans in patients with young adult hip pain carry a lifetime risk of malignancy. Arthroscopy. 2018;34(1):155-63 e3. https://doi.org/10.1016/j.a rthro.2017.08.235.

23. Cibere J, Russell D, Qian H, Forster BB, Wong H, Barber M, et al. Significant association of radiographic femoroacetabular impingement with early MRI features of hip disease: a population-based study. Osteoarthr Cartil. 2016;24: $22-3$.

24. Ito K, Minka MA 2nd, Leunig M, Werlen S, Ganz R. Femoroacetabular impingement and the cam-effect. A MRI-based quantitative anatomical study of the femoral head-neck offset. J Bone Joint Surg (Br). 2001;83(2): 171-6. https://doi.org/10.1302/0301-620X.83B2.0830171.

25. James SL, Ali K, Malara F, Young D, O'Donnell J, Connell DA. MRI findings of femoroacetabular impingement. AJR Am J Roentgenol. 2006;187(6):1412-9. https://doi.org/10.2214/AJR.05.1415.

26. Pfirrmann CW, Mengiardi B, Dora C, Kalberer F, Zanetti M, Hodler J. Cam and pincer femoroacetabular impingement: characteristic MR arthrographic findings in 50 patients. Radiology. 2006;240(3):778-85. https://doi.org/10.114 8/radiol.2403050767.

27. Samaan MA, Pedoia $V$, Zhang AL, Gallo MC, Link TM, Souza RB, et al. A novel mr-based method for detection of cartilage delamination in femoroacetabular impingement patients. J Orthop Res. 2018;36(3):971-8. https://doi.org/10.1002/jor.23667

28. Tresch F, Dietrich TJ, Pfirrmann CWA, Sutter R. Hip MRI: Prevalence of articular cartilage defects and labral tears in asymptomatic volunteers. A comparison with a matched population of patients with femoroacetabular impingement. J Magn Reson Imaging. 2017;46(2):440-51. https://doi.org/1 $0.1002 / j m r i .25565$.

29. Mygind-Klavsen B, Lund B, Nielsen TG, Maagaard N, Kraemer O, Holmich P, et al. Danish hip arthroscopy registry: predictors of outcome in patients with femoroacetabular impingement (FAI). Knee Surg Sports Traumatol Arthrosc. 2019;27(10):3110-20. https://doi.org/10.1007/s00167-018-4941-3.

30. Chai W, Xu M, Zhang GQ, Zhang LH, Gou WL, Ni M, et al. Computer-aided design and custom-made guide in corrective osteotomy for complex femoral deformity. J Huazhong Univ Sci Technol Med Sci. 2013;33(3):398405. https://doi.org/10.1007/s11596-013-1131-x.
31. Fucentese SF, Meier P, Jud L, Kochli GL, Aichmair A, Vlachopoulos L, et al. Accuracy of 3D-planned patient specific instrumentation in high tibial open wedge valgisation osteotomy. J Exp Orthop. 2020;7(1):7. https://doi.org/1 0.1186/s40634-020-00224-y.

32. Jud L, Vlachopoulos L, Haller TV, Fucentese SF, Rahm S, Zingg PO. The impact of mal-angulated femoral rotational osteotomies on mechanical leg axis: a computer simulation model. BMC Musculoskelet Disord. 2020;21(1): 50. https://doi.org/10.1186/s12891-020-3075-1.

33. Gyftopoulos S, Yemin A, Mulholland T, Bloom M, Storey P, Geppert C, et al. 3DMR osseous reconstructions of the shoulder using a gradient-echo based two-point Dixon reconstruction: a feasibility study. Skelet Radiol. 2013;42(3): 347-52. https://doi.org/10.1007/s00256-012-1489-z.

34. Liang $X$, Jacobs R, Hassan B, Li L, Pauwels R, Corpas L, et al. A comparative evaluation of cone beam computed tomography $(C B C T)$ and multi-slice $C T$ (MSCT) Part I. on subjective image quality. Eur J Radiol. 2010;75(2):265-9. https://doi.org/10.1016/j.ejrad.2009.03.042.

35. Malloy P, Gasienica J, Dawe R, Espinoza Orias AA, Nwachukwu BU, Inoue N, et al. 1.5 T magnetic resonance imaging generates accurate 3D proximal femoral models: surgical planning implications for femoroacetabular impingement. J Orthop Res. 2020;38(9):2050-6. https://doi.org/10.1002/jor.24 596.

36. Neubert A, Wilson KJ, Engstrom C, Surowiec RK, Paproki A, Johnson N, et al. Comparison of 3D bone models of the knee joint derived from CT and $3 T$ MR imaging. Eur J Radiol. 2017;93:178-84. https://doi.org/10.1016/j.ejrad.201 7.05.042.

37. Rathnayaka K, Momot KI, Noser H, Volp A, Schuetz MA, Sahama T, et al. Quantification of the accuracy of MRI generated 3D models of long bones compared to CT generated 3D models. Med Eng Phys. 2012;34(3):357-63. https://doi.org/10.1016/j.medengphy.2011.07.027.

38. Schneider PJ, Eberly DH. Geometric tools for computer graphics. Burlington: Morgan Kaufmann Publishers; 2003.

39. Koo TK, Li MY. A guideline of selecting and reporting intraclass correlation coefficients for reliability research. J Chiropr Med. 2016;12(2):155-63.

40. Samim M, Eftekhary N, Vigdorchik JM, Elbuluk A, Davidovitch R, Youm T, et al. 3D-MRI versus 3D-CT in the evaluation of osseous anatomy in femoroacetabular impingement using Dixon 3D FLASH sequence. Skelet Radiol. 2019;48(3):429-36. https://doi.org/10.1007/s00256-018-3049-7.

\section{Publisher's Note}

Springer Nature remains neutral with regard to jurisdictional claims in published maps and institutional affiliations.

Ready to submit your research? Choose BMC and benefit from:

- fast, convenient online submission

- thorough peer review by experienced researchers in your field

- rapid publication on acceptance

- support for research data, including large and complex data types

- gold Open Access which fosters wider collaboration and increased citations

- maximum visibility for your research: over $100 \mathrm{M}$ website views per year

At $\mathrm{BMC}$, research is always in progress.

Learn more biomedcentral.com/submissions 